Josep Aguiló Regla

«NOTA SOBRE "PRESUNCIONES” DE DANIEL MENDONCA» 


\section{NOTA SOBRE «PRESUNCIONES» DE DANIEL MENDONCA}

Josep Aguiló Regla

Universidad de Alicante

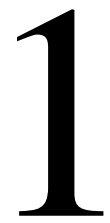

. Esta breve nota sobre «Presunciones» de Daniel Mendonca ${ }^{1}$ tiene su origen en una casualidad; no es en realidad el producto de ningún especial propósito intelectual sobre las presunciones legales. Estaba yo reseñando el artículo «Presunciones» de Daniel do en un «descanso» me acerqué al despacho de Daniel González Lagier para charlar y despejarme un poco. El azar quiso que en aquel momento Daniel G.L. estuviera tratando de desentrañar la distinción que algunos procesalistas hacen entre verdaderas presunciones y falsas presunciones (o entre presunciones en sentido estricto y presunciones aparentes). No viene al caso explicar las razones por las que Daniel G. L. estaba también en el asunto de las presunciones: su interés por ellas sin duda era genuino, pero tal vez no pudiera calificarse precisamente de intelectual. En cualquier caso, si bien las presunciones no figuraban en la agenda de ninguno de nosotros, iniciamos una interesante discusión. Del intercambio improvisado de ideas y opiniones que allí se produjo parecía seguirse algo que, según creo, Daniel Mendonca consideraría no muy adecuado. Esto es, que para dar cabal cuenta de las presunciones en el Derecho es preciso echar mano de la distinción entre reglas y principios; o dicho de otro modo, que hay presunciones que son (y operan como) reglas y hay presunciones que son (y operan como) principios. Junto a lo anterior, al final trataré de mostrar también que las llamadas «presunciones iuris et de iure» requieren un tratamiento diferenciado respecto de las otras presunciones: en particular, que su comprensión exige entrar de lleno en el marco de las normas constitutivas.

2. El interesante trabajo de Daniel Mendonca analiza (y en algunos puntos desarrolla y critica) el ensayo de Edna Ullmann-Margalit On Pre-

1 Mendonca, Daniel: «Presunciones», en Doxa 21-I, 1998, págs. 83-98. 
sumption ${ }^{2}$. A continuación, voy a reseñar brevemente algunas de las tesis asumidas por Daniel Mendonca. Para aligerar la exposición y no resultar engorroso, no me detendré a indicar si dichas tesis son el producto de una coincidencia con Edna Ullmann-Margalit o si son el producto de una crítica a esta autora.

2.1. La noción de presunción desempeña un papel importante en toda deliberación práctica y, por tanto, en el Derecho cobra especial relevancia. Las presunciones legales fuerzan a tomar algo como verdadero bajo determinados supuestos; en ocasiones, el Derecho interviene y establece reglas en forma de presunciones en virtud de las cuales se «infiere» un hecho controvertido, a partir de ciertos hechos básicos ya establecidos, mientras no se aporten elementos de prueba suficientes en sentido contrario. En rigor una regla de presunción establece lo siguiente: «Dado que es el caso de que $\mathrm{P}$, debe procederse como si $\mathrm{Q}$ fuese verdadero, a no ser que, o hasta que, existan razones suficientes para creer que no es el caso de que $Q »$.

2.2. Las presunciones legales son mandatos legislativos en virtud de los cuales se ordena tener por establecido un hecho, siempre que la ocurrencia de otro hecho, indicador del primero, haya sido comprobada suficientemente. Las presunciones legales son normas que imponen el deber de aceptar una proposición, siempre que otra proposición se encuentre debidamente probada. Imponen, pues, un deber muy particular: el deber de aceptar ciertas proposiciones en determinadas circunstancias especificadas por el sistema. En las presunciones legales, como en todos los demás casos de prescripciones, el contenido es una acción: en este caso, una acción peculiar pues consiste en un estado mental. La noción de aceptación está vinculada a las llamadas actitudes proposicionales. Conviene, sin embargo, deslindar claramente el plano lógico del psicológico sobre todo en el contexto de su empleo con fines justificativos. Aquí interesa la aceptación como actitud proposicional, como una operación de incorporación de proposiciones a razonamientos, es decir, de incorporación de premisas. Ahora bien, tales premisas son impuestas bajo el supuesto de la satisfacción de ciertas condiciones fijadas por las mismas normas que establecen presunciones: ciertas circunstancias deben darse para que entre a operar la obligación de presumir la proposición que la norma determina, es decir, la obligación de aceptar cierta proposición como premisa. Estas circunstancias remiten a la prueba de una proposición acerca de un estado de cosas determinado y a la ausencia de prueba respecto de la negación de la proposición presumida. Hay pues dos condiciones dominantes: Una positiva, la existencia de elementos

2 Ullmann-Margalit, Edna: «On Presumption», en The Journal of Philosophy, Vol. LXXX, no 3, Marzo 1983, págs. 143-163. 
de juicio a favor de una proposición determinada $(\mathrm{P})$ y otra negativa la ausencia de elementos de juicio a favor de la negación de la proposición presumida (Q).

2.3. Las presunciones cumplen un papel instrumental en el Derecho; su función básica es posibilitar la superación de situaciones de impasse del proceso decisorio, en razón de la ausencia de elementos de juicio a favor o en contra de determinada proposición. De este modo, la incorporación de presunciones constituye un mecanismo del que se vale el Derecho para resolver en un sentido determinado aquellos casos en que existe cierta incertidumbre acerca de si se han producido determinadas circunstancias. Un rasgo de las presunciones es la parcialidad, pues benefician a una de las partes. Esta parcialidad puede justificarse de diversas maneras: por consideraciones probabilísticas (es más/menos frecuente $\mathrm{Q}$ que $-\mathrm{Q}$ en caso de $\mathrm{P}$ ), por consideraciones valorativas (las consecuencias de presumir $\mathrm{Q}$ en $\mathrm{P}$ son más/menos graves que las de presumir -Q) y procesales (es más/menos fácil producir prueba en favor de $\mathrm{Q}$ que de $-\mathrm{Q}$, en caso de $\mathrm{P}$ ).

2.4. Las presunciones, suele decirse, son «vencibles», «superables», «derrotables», etc. La tradición jurídica distingue entre presunciones iuris et de iure y presunciones iuris tantum, es decir, entre presunciones que no admiten prueba en contrario y las que sí admiten tales pruebas, con o sin limitaciones. Hay que advertir que afirmar que no se admite prueba en contrario, no quiere decir que no pueda aportarse prueba para destruir el fundamento de la presunción, es decir, la proposición base. Lo que la ley no permite es atacar el enlace de la presunción o probar la inexistencia del hecho presumido, pero nada impide justificar que el hecho que se invoca como antecedente no existe (o no ha existido) o que no es el que específicamente requiere la ley. El efecto directo de la presunción legal es liberar a la parte a la que se beneficia de la carga que entraña la prueba de la proposición presumida, pero no de la proposición base. Y en cuanto la ley admita tal prueba y ella destruya el supuesto base, la presunción deja de surtir efecto.

2.5. Interesa pues distinguir dos estrategias diferentes destinadas a «atacar» una presunción:

A. La estrategia de bloqueo: La presunción «Dado P, se presumirá que Q» queda bloqueada en el caso c si, y solo si, se justifica que no está probado $\mathrm{p}$ en $\mathrm{c}$, o se prueba la negación de $\mathrm{p}$ en $\mathrm{c}$.

B. La estrategia de destrucción: La presunción «Dado P, se presumirá que Q» queda destruida en el caso c si, y sólo si, se prueba la negación de q en $c$.

«En ambos casos el efecto es el mismo: la presunción no entra a operar en el caso individual. La diferencia principal radica en la carga y dirección de la prueba: quien se beneficia de una presunción sólo debe probar la pro- 
posición base, mientras que quien pretende evitar ese beneficio debe producir prueba en sentido contrario, en alguna de estas dos direcciones: respecto de la proposición base o respecto de la proposición presumida. La estrategia de destrucción, obviamente, sólo puede ser empleada cuando la presunción atacada es una presunción iuris tantum» (pág. 98).

3. Hasta aquí las tesis de Mendonca que me interesaba resaltar; veamos ahora la distinción que algunos procesalistas trazan entre «presunciones en sentido estricto» $\mathrm{y}$ «presunciones aparentes o verdades interinas» ${ }^{3}$.

3.1. En las llamadas «presunciones en sentido estricto» se dan, según los procesalistas, tres elementos esenciales: un hecho base o indicio, un hecho presunto o presumido y una relación o nexo causal entre ellos. Así, si se acredita mediante prueba directa el hecho base, se tiene por cierto el hecho presunto. Estas presunciones implican, más que una inversión de la carga de la prueba, una modificación del thema probandi: la distribución de la carga de la prueba no se ve afectada en lo que se refiere a la iniciativa probatoria de las partes (no afecta al quién tiene que probar) pero sí a los hechos que se tienen que probar; pues el hecho presumido sólo podrá ser tenido en cuenta cuando la parte favorecida por él haya acreditado el hecho base. La parte contraria, cuando éste último haya sido probado, tendrá bien que atacar la prueba del hecho base, bien que atacar el hecho presumido. Un ejemplo de estas presunciones lo constituye el art. 1210 del Código civil, que establece una presunción de subrogación en el crédito cuando un tercero pague la deuda con aprobación del deudor. Para que la presunción pueda ser tenida en cuenta es necesario que el hecho base -el pago por un tercero con aprobación del deudor- quede probado, y si esto se produce, la contraparte tendrá que acreditar que el pago no se produjo, que se produjo sin aprobación del deudor o que, habiéndose producido, el efecto no ha sido el de la subrogación.

3.2. Frente a las anteriores están las llamadas «presunciones aparentes o verdades interinas». Lo característico en ellas es que si bien adoptan la forma (la apariencia) de presunciones, en realidad su única función es la de establecer un reparto del onus probandi. En este sentido, por ejemplo, escribe Manuel Serra Domínguez: «[para] establecer reglas legales de distribución de la carga de la prueba se vale el legislador de dos diversos expedientes: A) Establecer directamente una regla de carga de la prueba, grabando a una de las partes con la prueba de un hecho determinado [por ejemplo, el art. 850 del Código civil establece que «la prueba de ser cierta la causa de la desheredación corresponderá a los herederos del testador, si el des-

${ }^{3}$ En este punto sigo a Mercedes Fernández López: La carga de la prueba en el proceso civil, Tesis de licenciatura, Alicante, 2000. 
heredado lo negare»]. B) «Crear falsas presunciones que no tienen otra finalidad que enmascarar las reglas sobre la carga de la prueba» [por ejemplo, el art. 434 del Código civil establece que «la buena fe se presume siempre, y al que afirma la mala fe de un poseedor corresponde la prueba»] ${ }^{4}$. De acuerdo con este planteamiento las reglas que establecen «falsas presunciones» no serían más que un modo indirecto de establecer reglas sobre la carga de la prueba. Así, por ejemplo, la regla contenida en el art. 1183 del Código civil, que dice que «siempre que la cosa se hubiese perdido en poder del deudor, se presumirá que la pérdida ocurrió por su culpa y no por caso fortuito, salvo prueba en contrario», bien podría haberse redactado sin menoscabo alguno simplemente diciendo que «en caso de pérdida de la cosa debida, la prueba del caso fortuito corresponde al deudor» ${ }^{5}$.

3.3. La clave de la distinción entre «presunciones en sentido estricto» y «presunciones aparentes» parece radicar, pues, en lo siguiente: Las «presunciones en sentido estricto» no afectan a la carga de la prueba (quién tiene que probar), sino sólo al tema de la prueba (qué hay que probar); benefician a una parte, en cuanto que le facilitan la prueba, pero no exoneran a nadie de la necesidad de probar: la parte beneficiada tendrá siempre, como mínimo, que probar el hecho base. Por el contrario, las «presunciones aparentes» son estrictamente reglas de la carga de la prueba; en consecuencia, la parte favorecida no tiene que acreditar hecho base o indicio alguno: queda exonerada de la prueba de cualquier hecho relacionado con el hecho presunto.

4. El propósito de esta nota -ya lo dije al principio- no es estudiar a fondo las presunciones, sino más bien formular algunas hipótesis que de confirmarse mostrarían, por un lado, la insuficiencia de los esquemas que -como el asumido por Mendonca- están basados exclusivamente en la noción de regla de presunción y, por otro, pondrían en cuestión ciertas afirmaciones de algunos procesalistas. La estrategia argumentativa que voy a seguir es muy sencilla: recurriré a Mendonca para cuestionar a los procesalistas y recurriré a estos últimos para cuestionar a Mendonca.

4.1. En primer lugar, si bien es cierto que en el trabajo de Mendonca no hay referencia alguna a lo que los procesalistas llaman «falsas presunciones» $\mathrm{o}$ «presunciones aparentes», siguiendo sus afirmaciones no se encuentran razones para excluir a estas presunciones de la clase de las presunciones legales; y, si ello es así, no se ve por qué deban reducirse a simples reglas de la carga de la prueba. En efecto, las «falsas presunciones» o «verdades interinas» ordenan algo muy semejante a lo que Mendonca atribuía a las reglas de presunción: establecen que debe procederse como si Q fuese

\footnotetext{
${ }^{4}$ Serra Domínguez, M. y Gutiérrez de Cabiedes y Cordón Moreno, F.: Comentarios al Código Civil y a las Compilaciones Forales, Vol. XVI, T. 2, Madrid, 1992, pág. 52.

${ }^{5}$ Cfr. Fernández López, Mercedes: ob. cit., pág. 148.
} 
verdadero, ordenan tener por establecido un hecho. El deber que imponen es tan peculiar como el de las reglas de presunción (o «presunciones en sentido estricto»): su contenido consiste en aceptar ciertas premisas. Además, de ellas pueden predicarse también las notas de la parcialidad (favorecen a una parte) y de la derrotabilidad o superabilidad. Luego, si lo anterior es cierto, parece que la pretensión de los procesalistas de reducir estas presunciones a reglas de la carga de la prueba resulta infundada. Naturalmente, ellas inciden sobre la carga de la prueba, pero su contenido no se agota en eso: el mandato de tener por establecido un hecho implica que, a falta de prueba, el Derecho no suspende el juicio, sino que ordena aceptar una premisa que afirma como verdadera la ocurrencia de ese hecho. La diferencia entre verlo de una forma u otra puede mostrarse claramente a partir de un ejemplo: Conforme a lo ordenado por la presunción de la buena fe en la posesión, del hecho de que la mala fe no resulte probada no se sigue sólo que las consecuencias jurídicas de la mala fe no sean aplicables, sino también la obligación de aceptar la premisa de que la posesión ha sido de buena fe.

4.2. En segundo lugar, si lo anterior es correcto tal vez tenga sentido suponer -en contra de lo afirmado por Mendonca- que al menos algunas presunciones no cumplen exclusivamente una función instrumental consistente en superar situaciones de impasse del proceso decisorio. En este contexto, la palabra «instrumental» puede resultar algo engañosa; porque una cosa es decir que todas las normas pueden ser vistas como instrumentos para la protección o promoción de ciertos bienes o valores jurídicos (y en este sentido las normas de presunción no serían diferentes de las otras normas) y otra cosa es decir que el único bien que tratan de proteger es el proceso de decisión. En mi opinión, el sentido de muchas presunciones legales no es sólo (ni fundamentalmente) superar situaciones de impasse. La nota de la parcialidad de las presunciones (destacada por Mendonca) hace plausible la hipótesis de que muchas de ellas cumplen una función garantista que va mucho más allá de la meramente instrumental en relación con el proceso de decisión; lo que, a su vez, permitiría explicar por qué algunas de esas presunciones son concebidas como garantías. Si ello es así, me parece claro que la pretensión de algunos procesalistas de reducir todas las «presunciones aparentes» a reglas de la carga de la prueba (lo que en algunos casos podría suponer reducir las garantías a cargas) se hace acreedora de todas las críticas que en el ámbito del Derecho sustantivo se han dirigido a la tesis de la reductibilidad de los derechos a deberes ${ }^{6}$. En un caso se sostendría que un

${ }^{6}$ Para una crítica a la tesis de la correlatividad entre derechos y deberes (o, en la terminología aquí asumida, a la tesis de la reductibilidad de los derechos a deberes), véase Laporta, Francisco: «Sobre el concepto de derechos humanos», en Doxa, n 4, 1987. 
enunciado que afirma que uno tiene un derecho se reduce a un enunciado de que otro tiene un deber; en el otro, que un enunciado que afirma que alguien es titular de la garantía procesal que representa la presunción se reduce a un enunciado de que otro tiene una carga procesal de probar $^{7}$. Estas reducciones ignorarían las relaciones de justificación y estarían confundiendo los bienes o valores jurídicos (en definitiva, los títulos) con las técnicas normativas diseñadas para su protección. Un corolario de esta hipótesis sería que mientras que tiene pleno sentido afirmar que alguien tiene una carga porque otro tiene una garantía, no lo tendría afirmar que alguien tiene una garantía porque otro tiene una carga.

4.3. En otro lugar, siguiendo en parte un esquema propuesto por Atienza y Ruiz Manero ${ }^{8}$, he dicho que la mejor manera de caracterizar desde una perspectiva estructural la distinción entre reglas y principios es recurriendo a la caracterización que Von Wright hace de las normas categóricas. Los principios son un tipo de pauta de conducta, de normas cuyas condiciones de aplicación derivan exclusivamente de su contenido; y, en este sentido, constituyen mandatos incondicionados. A diferencia de ellos, las reglas son normas que sí cuentan con condiciones de aplicación adicionales a las que derivan de su propio contenido; por ello en su formulación adoptan típicamente una estructura condicional. Naturalmente, todas las normas jurídicas, sean principios o reglas, son prima facie, ninguna de ellas contiene mandatos absolutos. La estructura categórica o hipotética de las normas jurídicas no afecta a su carácter de derrotables, sino a la forma en que pueden ser derrotadas ${ }^{\text {. }}$.

Pues bien, todo esto tiene que ver con lo siguiente, y ahí va la tercera hipótesis: Tal vez una buena manera de dar cuenta de la distinción de los procesalistas entre «presunciones en sentido estricto»y «presunciones aparentes» sería recurrir a la distinción entre reglas y principios. Si se acepta que todas las presunciones responden a normas de presunción con el contenido peculiar que Mendonca les atribuía, entonces podría decirse que hay presunciones establecidas por reglas y presunciones establecidas por principios; en particular, las llamadas «presunciones en sentido estricto» serían

${ }^{7}$ En este punto conviene introducir dos matizaciones para evitar malentendidos: Primera, no estoy afirmando que todas las garantías procesales se tengan frente a la otra parte del proceso; muchas de ellas no son explicables en términos de una relación entre las partes. Y segunda, no estoy manejando una semejanza de términos que pudiera llevar a considerar que propongo ver a las cargas procesales como deberes y cosas por el estilo; para formular la hipótesis he recurrido no a una semejanza de términos, sino a una semejanza de relaciones.

${ }^{8}$ Atienza, Manuel y Ruiz Manero, Juan: Las piezas del Derecho. Teoría de los enunciados jurídicos, Ariel, Barcelona, 1996.

9 Aguiló Regla, Josep: Teoría general de las fuentes del Derecho (y del orden jurídico), Ariel, Barcelona, 2000, págs. 136 y ss. 
presunciones-regla y las «presunciones aparentes», presunciones-principio. La diferencia estructural entre ellas está clara: en las primeras, la obligación de aceptar Q depende de ciertas circunstancias, básicamente de la prueba de P; en las segundas, la obligación de aceptar Q no está sometida a condición alguna. Si uno se da cuenta de ello, entonces a lo mejor es posible relacionar esta diferencia estructural con algunas diferencias funcionales, así como con las diferentes estrategias encaminadas a desactivar una presunción. En efecto, las presunciones-principio (tales como la presunción de inocencia, la de la buena fe, etc.), las que operan de manera incondicionada (no tienen más condiciones que las que derivan de su contenido), tienen un alcance justificativo mucho mayor que las otras, lo que les atribuye un papel mucho más importante en la conformación del propio proceso y de la decisión final. Este papel conformador se ve claro cuando uno se da cuenta de que influyen no en el thema probandi, sino en el onus probandi; lo que a su vez se traduce en que la única estrategia disponible para desactivarlas es la de la destrucción de la presunción, es decir, probar no Q. Por el contrario, las presunciones-regla juegan, me parece, un papel conformador del propio proceso mucho menor $\mathrm{y}$, en muchos casos, tal vez pueda pensarse que, en efecto, centralmente cumplen esa función instrumental en relación con el proceso de decisión de superar situaciones de impasse. Por ello, si bien presentan también la nota de la parcialidad, pues facilitan la prueba a una de las partes (alteran el qué tiene probar la parte beneficiada), no se traducen en una inversión de la carga de la prueba (no afectan al quién tiene que probar). En relación con ellas, en la medida en que sean iuris tantum, caben las dos estrategias de desactivación de la presunción: la estrategia de bloqueo y la estrategia de destrucción.

Esta tercera hipótesis, la de que hay presunciones-principio y presunciones-regla, puede reforzarse imaginando cómo afectaría a nuestro Derecho civil un cambio legislativo en relación con algunas de ellas. Me parece claro que si por ejemplo la buena fe en la posesión dejara de presumirse y tuviera que ser probada se consideraría que se ha producido un cambio normativo cuyo alcance nadie lo reduciría a una simple modificación de las técnicas para superar situaciones de impasse; cosa que me parece que no ocurriría si se modificase la presunción de subrogación en el crédito por el pago de un tercero con aprobación del deudor.

4.4. Si bien se considera, y si lo anterior es acertado, podría establecerse una correspondencia entre tipos de presunciones y estrategias disponibles para su desactivación.

4.4.1. Las presunciones-principio sólo pueden ser destruidas: dado que la obligación de aceptar como premisa la proposición presumida no está condicionada a la prueba de la verdad de ninguna otra proposición, no cabe 
la posibilidad del bloqueo; toda la prueba está orientada a mostrar la falsedad de la proposición presumida. La asimetría que estas presunciones generan entre las partes (liberan a una de ellas de cualquier carga probatoria) es precisamente lo que hace plausible la hipótesis consistente en atribuirles el rol esencialmente garantista y conformador del propio proceso al que más arriba se ha aludido.

4.4.2. Las presunciones-regla iuris tantum pueden ser desactivadas recurriendo tanto a la estrategia del bloqueo como a la de la destrucción; es decir, mostrando que o no se dan (o no han quedado acreditadas) las circunstancias que condicionan la obligación de aceptar la proposición presumida (que el antecedente no ha quedado probado), o la falsedad de la proposición presumida. Estas presunciones, obviamente, no liberan a ninguna de las partes de la carga de probar; de ahí, del hecho de que la asimetría que generan sea mucho menor, resulta plausible la hipótesis de que su función es ciertamente orientadora (más que conformadora) del proceso de decisión; o, como decía Mendonca, están destinadas a superar situaciones de impasse en el proceso decisorio.

4.4.3. Las presunciones-regla iuris et de iure sólo pueden ser bloqueadas, ellas vedan destruir el nexo entre el antecedente y el consecuente; de forma que si queda acreditado el antecedente, entonces queda «necesariamente» acreditado el consecuente.

4.5. Finalmente, quiero introducir algunos comentarios en torno a estas últimas presunciones, las presunciones iuris et de iure. Es obvio que el Código civil español las reconoce en su art. 1251, pero también lo es que no resulta nada fácil encontrar ejemplos claros de las mismas y que, además, se trata una figura jurídica altamente controvertida ${ }^{10}$. En cualquier caso, como se ha visto, para poder hablar de presunción iuris et de iure deben darse estos tres requisitos: a) una proposición base cuya verdad debe probarse; b) una proposición presumida cuya verdad debe aceptarse; y c) una prohibición de prueba en contra de la verdad de la proposición presumida. Por ello, como decía Mendonca, estas presunciones pueden ser bloqueadas pero no destruidas. Ahora bien, esa tercera característica parece arrojar a la proposición presumida fuera del ámbito de las proposiciones; sea cual sea su apariencia no parece ser un buen candidato para expresar ninguna verdad

${ }^{10}$ En este sentido, por ejemplo, ha escrito Carlos S. Nino: «[...] el consenso democrático no puede funcionar como criterio de verdad fáctica para fundamentar la legitimidad jurisdiccional. Son incompatibles con los principios de una democracia liberal las leyes que preconstituyen hechos particulares, creando ficciones o presunciones iuris et de iure, como los llamados "delitos de peligro abstracto"; ellas implican que los poderes políticos se arrogan una función inherente al Poder Judicial» [en Fundamentos de Derecho Constitucional. Análisis filosófico, jurídico y politológico de la práctica constitucional, Ed. Astrea, Buenos Aires, 1992, pág. 450.]. 
fáctica, no se ve qué función veritativa pueda cumplir. A partir de ahí, y más allá de las cuestiones puramente verbales, tal vez haya razones para expulsar a las «presunciones iuris et de iure» del mundo de las presunciones, estipulando que el ámbito en el que las presunciones operan es el de la verdad fáctica. Adonde apunto es a lo siguiente: en mi opinión, meter en el mismo «saco» a todas las «presunciones» lleva a confundir dos relaciones que me parecen claramente diferentes: la relación entre hecho probado y hecho presumido, por un lado, y la relación entre hecho probado y hecho constituido (o resultado institucional), por otro. La primera relación tiene que ver con los hechos del caso, afecta a la verdad fáctica, su ámbito es, por decirlo de algún modo, el mundo «natural» $\mathrm{y}$, por tanto, se sitúa en el terreno de la prueba. Éste es, me parece, el ámbito en el que las presunciones, si bien están normativamente impuestas, cumplen una función veritativa: su contenido -como veíamos- consiste en aceptar como premisa una proposición. La segunda, por el contrario, tiene que ver con la calificación jurídica de los hechos del caso, su ámbito es el paso de los hechos del caso a los resultados institucionales y, por tanto, se sitúa fuera del ámbito de la prueba: el problema aquí no es determinar qué ha ocurrido (lo que constituiría un problema de prueba), sino cómo calificar lo ocurrido con el fin de atribuirle unas $\mathrm{u}$ otras consecuencias jurídicas ${ }^{11}$. Éste es el ámbito en el que hay que ubicar en mi opinión a la mayoría de situaciones que los juristas consideran presunciones iuris et de iure porque, en realidad, más que una prohibición de prueba, en ellas lo que hay es una simple imputación normativa y, obviamente, éstas no pueden ser objeto de prueba. Para ilustrar la confusión que supone ver como presunciones a simples cuestiones de calificación me voy a valer de un ejemplo traído del Derecho tributario aunque, ciertamente, simplificado y retocado. Imaginemos una regla en materia fiscal que estableciera que las donaciones realizadas durante los cinco años anteriores a la muerte del causante se entenderán hechas a título sucesorio y que el tratamiento fiscal de la donación fuera diferente del de la sucesión. Situaciones semejantes a ésta son tratadas en ocasiones como presunciones (iuris et de iure, pero presunciones al fin y al cabo); sin embargo, en mi opinión, difícilmente pueden explicarse a la luz de la relación entre hecho probado y hecho presumido, puesto que en realidad no se presume ningún nexo entre hechos «naturales» susceptible de ser bloqueado o destruido. Lo que hay es un único hecho «natural» que bajo ciertas condiciones da lugar al resultado institucional donación (con las consecuencias jurídicas que de él se siguen) y que bajo otras condiciones da lugar al resultado institucional sucesión

\footnotetext{
${ }^{11}$ Para una exposición detallada de la dimensión constitutiva del Derecho y una crítica de la noción estándar de «hecho jurídico» puede verse Aguiló Regla, Josep: ob. cit, págs. 52 y ss.
} 
(con las consecuencias jurídicas que de él se siguen). Pero en ambos casos la conexión entre el hecho probado (lo ocurrido) y el resultado institucional es convencional y normativa, no cumple ninguna función veritativa y no obliga al juez a aceptar (tener por cierta) ninguna proposición relativa a los hechos del caso. Este tipo de situaciones poco tienen que ver con las presunciones; en realidad, no hay prohibición de prueba: habrá que probar la verdad fáctica (lo ocurrido, el hecho «natural» y sus circunstancias) para después determinar si el resultado institucional es la donación o la sucesión.

Algo bastante parecido puede decirse de otras situaciones jurídicas que la doctrina ha explicado como ficciones legales (figura ésta -la de las ficciones- que en no pocas ocasiones ha sido tratada de manera muy semejante a las presunciones iuris et de iure ${ }^{12}$ ). Considérese el ejemplo típico de la ficción del concebido no nacido establecida en el art. 29 del Código civil que dice que «el nacimiento determina la personalidad; pero el concebido se tiene por nacido para todos los efectos que le sean favorables...» ${ }^{13}$. Este artículo ciertamente no finge ningún hecho natural, no obliga al juez a aceptar ninguna premisa relativa a los hechos, ni tampoco establece ninguna prohibición de prueba relativa a que el nacimiento del concebido no nacido no se ha producido. A lo único que obliga es a aplicar al concebido no nacido algunas de las consecuencias jurídicas que se siguen de la atribución de personalidad. Y ello, obviamente, no puede ser destruido mediante prueba porque nada tiene que ver con la prueba.

El origen de todas estas confusiones se sitúa me parece en una concepción profundamente esencialista de la relación entre hechos naturales y hechos constituidos (o resultados institucionales), que lleva a pensar por ejemplo cosas tales como que la imputación jurídica de la paternidad (hecho constituido o resultado institucional) implica necesariamente o bien una presunción de la paternidad biológica (hecho natural) o bien una ficción deformadora de la realidad (ficción de la paternidad biológica). Si se es cons-

${ }_{12}$ A propósito de esta semejanza escribe Regina Garcimartín Montero [en El objeto de la prueba en el proceso civil, Cedecs, Barcelona, 1997, pág. 74], «Además de las presunciones, se puede producir también una fijación del hecho a través de las ficciones; no se trata de una figura jurídica que tenga naturaleza idéntica a las presunciones iuris et de iure, sino que entre ambas existen ciertas diferencias: la ficción tiene carácter material, frente al carácter procesal de la presunción; además, la presunción supone consagrar legalmente una máxima de experiencia, mientras que la ficción no obedece necesariamente a criterios de búsqueda de la verdad, de forma que, así como la ficción finge lo falso, la presunción intenta alcanzar la verdad.

«Sin embargo, ninguna de estas diferencias afecta al tratamiento que tanto las ficciones como las presunciones iuris et de iure reciben en el proceso, ya que en ambos casos lo que se da es una prohibición de prueba del hecho ya determinado legalmente»

${ }^{13}$ Para un análisis de esta ficción puede verse Hernández Marín, Rafael: «Ficciones jurídicas», en Doxa, $\mathrm{n}^{\circ}$ 3, 1986. 
ciente del carácter convencional (y normativo) de esta relación, entonces es fácil darse cuenta de que la imposición por parte del legislador de un resultado institucional en lugar de otro no implica necesariamente una presunción sobre ninguna verdad fáctica, ni ninguna ficción deformadora de la realidad. Estas consideraciones me llevan a pensar que, más allá de las cuestiones puramente verbales heredadas de la tradición jurídica, no puede darse una explicación unitaria de todos los fenómenos denotados por el rótulo «presunciones legales». Algunos de estos fenómenos pueden explicarse como intervenciones normativas referidas a la verdad fáctica y se traducen en la obligación de aceptar una proposición (proposición que por su propia naturaleza tiene que ser susceptible de ser falsada, esto es, destruida). Otros fenómenos, como las presunciones iuris et de iure y las ficciones, difícilmente pueden explicarse desde los parámetros anteriores. La clave para su comprensión radica en desvincularlos del ámbito de la verdad fáctica y resituarlos en el ámbito de la constitución de resultados institucionales y de la imputación de consecuencias jurídicas. Desarrollar esta idea requiere, por un lado, echar mano de la noción de regla puramente constitutiva y, por otro, romper la ambigüedad con que los juristas usan la expresión «hecho jurídico» ${ }^{14}$. Pero todo ello está muchísimo más allá de las pretensiones con las que inicié este trabajo.

\footnotetext{
${ }^{14}$ Las reglas puramente constitutivas establecen que si se da un determinado estado estado de cosas se produce un determinado resultado institucional o cambio normativo y su forma canónica es «Si se da el estado de cosas X, entonces se produce el resultado institucional R». Así, por ejemplo, la regla que establece la mayoría de edad sería reformulable en los siguientes términos: «si se da el estado de cosas X (tener 18 años cumplidos), entonces se produce el resultado $\mathrm{R}$ (mayoría de edad). El carácter constitutivo de estas reglas proviene de que ellas crean la posibilidad de que se dé el resultado institucional. Cfr. Atienza, Manuel y Ruiz Manero, Juan: ob. cit., pág. 166. La ambigüedad de la expresión «hecho jurídico» proviene de que los juristas unas veces la usan para referirse a los hechos del caso y otras, a la calificación de los hechos o al nomen iuris con el que se designa el resultado institucional. Así, en relación con el ejemplo anterior, la expresión «hecho jurídico» se usa indistintamente para referirse al supuesto de hecho (tener 18 años cumplidos) como al resultado institucional (mayoría de edad). Cfr. Aguiló Regla, Josep: ob. cit., págs. 54 y ss. Naturalmente, el estado de cosas X puede ser objeto de prueba (para determinar si se han cumplido o no los 18 años de edad), pero el paso de la X a la $\mathrm{R}$ (de los 18 años a la mayoría de edad) no.
}

\section{DOXA 22 (1999)}

